\title{
A Rights-Based Approach to Youth Sexting: Challenging Risk, Shame, and the Denial of Rights to Bodily and Sexual Expression Within Youth Digital Sexual Culture
}

\author{
Emily Setty ${ }^{1}$ (C) \\ Published online: 26 November 2019 \\ (C) The Author(s) 2019
}

\begin{abstract}
Educational interventions on youth sexting often focus on individual sexters or would-be sexters, and are driven by the aim of encouraging young people to abstain from producing and sharing personal sexual images. This approach has been criticised for failing to engage with the complex sociocultural context to youth sexting. Drawing upon qualitative group and one-to-one interviews with 41 young people aged 14 to 18 living in a county in south-east England, I explore young people's perceptions and practices surrounding sexting. By taking a grounded theory approach to the research, I reveal how young people's shaming of digitally mediated sexual self-expression shaped and was shaped by a denial of rights to bodily and sexual autonomy and integrity. This denial of rights underpinned harmful sexting practices, including violations of privacy and consent, victim blaming, and bullying. I conclude that responses to youth sexting should attend to this broader youth cultural context, emphasise the roles and responsibilities of bystanders, and encourage a collectivist digital sexual ethics based upon rights to one's body and freedom from harm (Albury, New Media and Society 19(5):713-725, 2017; Dobson and Ringrose, Sex Education 16(1):8-21, 2015).
\end{abstract}

Keywords Sexting $\cdot$ Young people $\cdot$ Digital ethics $\cdot$ Bystander intervention

\section{Introduction}

Sexting involves the digital production and exchange of personal sexual messages and images (Hasinoff 2015). There is ongoing public preoccupation with young people's involvement in sexting, or youth sexting as the phenomenon has been termed. While increasingly characterised as a developmentally normative adolescent activity in scholarly circles, youth sexting tends to be depicted as inherently risky and harmful in mainstream public debate about the phenomenon (Albury 2017; Döring 2014; Hasinoff 2015, 2017). In this context, youth sexting is delegitimised as a phenomenon. It is attributed to the supposed pernicious effects of technology on young

Electronic supplementary material The online version of this article (https://doi.org/10.1007/s42380-019-00050-6) contains supplementary material, which is available to authorized users.

Emily Setty

e.setty@surrey.ac.uk

1 Sociology Department, Faculty of Arts and Social Sciences, University of Surrey, Guildford, Surrey GU2 7XH, UK people, who are believed to sext as a result of being overexposed to sexualised content in their day-to-day cultural contexts (Draper 2012; Lee et al. 2013; Lunceford 2010).

In this article, I present findings from qualitative group and one-to-one interviews with young people exploring their practices and perceptions surrounding sexting. The research focused on how they constructed and navigated the ethics of sexting, in terms of privacy and consent. The analysis revealed that harmful sexting practices - including violations of privacy and consent, victim blaming, and bullying - involved the social shaming of (some) young people who sext and were predicated upon a denial of rights to bodily and sexual expression. I argue that addressing harmful sexting practices requires linking situated interpersonal and social harms to broader sociocultural meanings, norms, and processes. My participants collectively contributed to making sexting meaningful and, therefore, had roles and responsibilities as bystanders in youth sexting culture (Bailey and Mouna 2011; Crofts et al. 2015).

These findings pose challenges to constructions of youth sexting as inherently harmful and the abstinence-based sex education and campaigning that seeks to warn young people about the risks of sexting (see Moran-Ellis 2012). In these 
contexts, young women, in particular, are depicted as being at risk of being pressured or coerced into sexting by young men who later distribute their images without their consent (Döring 2014; Draper 2012; Herriot and Hiseler 2015). Social shaming and bullying of exposed sexters are depicted as inevitable (Dobson and Ringrose 2015). Sexting has, therefore, been conceptualised as either a form of or directly linked to bullying within the peer group (see Dake et al. 2012; Lee and Crofts 2015; Ringrose et al. 2013; Shariff and DeMartini 2015).

It is argued that sexting is distinct from bullying because it can be voluntarily chosen, and far from all young people who sext say they experience bullying (Dake et al. 2012; Wilkingson et al. 2016). Sexting can, however, involve or lead to bullying. Images can be distributed without the consent of the subject (who can then experience shaming or harassment from peers), and individuals (often young women) can experience pressure to engage in sexting or can be sent unsolicited images without their consent (often by young men) (Angrove 2015; Ringrose et al. 2013; Shariff and DeMartini 2015). While not all youth sexting is harmful, particular types of young people may be at heightened risk of abuse and bullying (Lee and Crofts 2015; Cooper et al. 2016). Through interviews with young people in Canada, Mishna et al. (2018) show how gendered and sexualised bullying and cyberbullying is shaped by a normalisation of gender and sexual stereotypes. They found that girls and young women are subject to scrutiny and held responsible for the behaviours of boys and young men. Similar processes have been found to occur in youth sexting culture (e.g. Ringrose et al. 2012).

It is suggested that education and campaigning should challenge harmful practices and connect young people's sexting experiences to the broader sociocultural context in which sexting occurs (Albury et al. 2013; Renold 2016; Lloyd 2018). Most recent guidance to schools recommends educational, support and safeguarding responses to sexting incidents (UKCCIS 2017). It specifies that schools should distinguish between harmful, aggravated, and adult-involved incidents (in which the police should be notified and school safeguarding procedures followed) and youth-only, developmentally normative sexting, which can be dealt with informally within the school (see Wolak and Finkelhor 2016). The guidance recommends avoiding causing young people to feel any further shame for sexting. Also advocated is proactive education, in which young people are spoken to about managing risks, resisting sexting and seeking support, as well as broader themes around consent, healthy relationships, rights and respect, abuse and coercion, and responsibilities toward others.

The guidance can be commended for taking a holistic approach, deemphasising legal enforcement, and discouraging reinforcing any shame a young person may be feeling. However, youth sexting is still presented as a problem and there is little on specifics regarding how schools can engage with the broader context to youth sexting. In a study of educational responses to youth sexting, Lloyd (2018) found that schools struggle to know what to do and responses vary from minimal to "knee-jerk" (p. 11). In this article, I seek to contribute to the debate on how youth sexting should be responded to and addressed within educational contexts. Such a contribution is pertinent and timely given that Sex and Relationships Education (SRE) is to become mandatory in most schools in England and Wales from 2020 (DfE 2018). I argue that SRE should attend to the broader youth cultural context surrounding sexting, emphasise the roles and responsibilities of bystanders, and encourage a collectivist digital sexual ethics based upon rights to one's body and freedom from harm (Albury 2017; Dobson and Ringrose 2015).

\section{Young People's Perspectives on Sexting}

Sexting may not necessarily be a new norm, in the sense that not all or even most young people report sharing selfproduced images (see Burén and Lunde 2018; Klettke et al. 2014). Yet, qualitative research suggests that it is normalised as a phenomenon within young people's peer cultures. In a study conducted with young people in two inner-city London secondary schools, Ringrose et al. (2012) found that young people's sexting practices reflect and reinforce a wider youth cultural context characterised by sexist and sexualised harassment and abuse. Young women came under pressure to engage in sexting to please young men, but gender double standards meant they risked slut shaming if exposed as sexters. Young men, meanwhile, were lauded and able to seek social capital through the accomplishment of obtaining and distributing images of young women. Other studies similarly reveal sexting to be a gendered phenomenon (Albury et al. 2013; Coy et al. 2013; Harris et al. 2013; Lippman and Cambell 2014; Phippen 2012; Walker 2012).

Technology seems, therefore, to be amplifying problems located within peer culture (Ringrose and Harvey 2015). The aforementioned studies found that gender double standards and harmful sexting practices are taken-for-granted by young people. This can lead to victim blaming as young people consider it up to individuals to anticipate and manage risk. In research with Belgian teenagers, De Ridder (2017, 2018) found that risk and individualising discourses meant that sexting, regardless of context, was defined as stupid. His participants engaged in moralising and normalising judgments, in which sexual self-expression was shameful and stigmatising. He argues that sexting is about transgressing a norm, which works to normalise shaming responses. However, he also found that there is potential for value and social capital, which underpins harmful practices like unauthorised distribution of images (De Ridder 2018). The question is, whose capital and in what circumstances? 
On individual and interpersonal levels, sexting is not always experienced by young people as harmful (Crofts et al. 2015). Research by Albury et al. (2013), for example, found that young people distinguish between abusive sexting contexts characterised by violations of privacy and consent, and more positive contexts in which self-produced images are used for purposes relating to experimentation, bonding, trust, intimacy, and fun. Young people can be critical of what they perceive to be negative and judgmental sex education discourses (Jørgensen et al. 2018). However, the tendency for young people to be risk averse and individualistic about sexting may be a result of their exposure to these institutional and cultural risk and harm discourses (Crofts et al. 2015; De Ridder 2017, 2018). Imperative, it seems, it recognising sexting as both a situated individual and interpersonal practice, and a youth cultural phenomenon made meaningful through norms and value systems which shape how individuals act and are treated by one another (Crofts et al. 2015).

To return to the question about social capital, it is, therefore, the meanings within young people's peer cultures that shape risk and reward in sexting (Lloyd 2018; Ringrose and Harvey 2015; Dobson 2018). In research with Australian young adults, Clancy et al. (2019) found that unauthorised distribution of images is associated with beliefs that distributing the images of others is "no big deal", may enhance the social status of the distributor, and is "acceptable" and "funny" (p. 270). The authors conclude that dissemination is an "exchange behaviour whereby sexts are traded or shared broadly within groups, creating a group norm and expectation that sexts will be disseminated, and reducing any barriers to engaging in dissemination behaviours" (p. 271). The broader peer group - or audience-is, therefore, relevant to giving sexting meaning and shaping sexting practices (Hasinoff 2015; Powell 2010). Naezer and Ringrose (2018) argue that technology may provide opportunities for different practices and may free young people from the purview of adults. They suggest, however, that online spaces represent sites of control, surveillance, and social policing by and among young people (also see De Ridder 2018). They contend that " "[ $t]$ he public' is thus not absent from 'the private', and public norms, practices, and institutions influence which 'private', intimate practices and feelings are legitimate and rewarding" (ibid: 417).

\section{Digital Rights vs. Protection from Harm}

It has been suggested that youth sexting practices should be conceptualised as ranging along a continuum, in which harm arises from violations of privacy and consent, rather than being inherent to the production of personal sexual images (Hasinoff 2015; Lee and Crofts 2015). Such a conceptualisation subsequently entails asking whether young people can be given a right to sext and protection from harm (Gillespie 2013). Young people are rarely talked about in terms of digital rights and tend, instead, to be seen as vulnerable (Livingstone and Third 2017). A denial of rights is conceived of in terms of maintaining their "innocence" and protecting them from the dangers of sex and sexuality (Simpson 2013, p. 699). This means they are told to abstain from sexting, but little thought it given as to whether this will help protect them from the harms emanating from their peer contexts.

Hasinoff (2017) argues that there is a preoccupation with communicating anti-sexting messages and encouraging abstinence. She suggests that this can result in a lack of justice for victims of harmful sexting practices, because they are labelled the problem for choosing to produce and share images. These messages obscure the role of bystanders who contribute to giving sexting meaning and act as the powerful audience that collectively define particular sexting practices and actors as shameful, while bestowing social capital on others (Hasinoff 2015; Powell 2010). Such social processes can legitimise and normalise particular courses of action in youth sexting culture, for example the decision to non-consensually distribute an image (Clancy et al. 2019; Crofts et al. 2015). Angelides (2013) advocates attending to the broader context underpinning harmful practices, including, in particular, the cultural objectification and commodification of women's bodies which mean that images of girls and young women hold value within the peer group.

It is suggested that the discounting of girls' and young women's rights and experiences, alongside the construction of boys' and young men's inherent sexuality and entitlement, underpins harmful sexting practices (Ringrose et al. 2012; Dobson and Ringrose 2015). Tolman et al. (2015) argue that girls and young women are rarely acknowledged as sexual subjects and, while they are implored to say no, there is little option for them to engage in volitional legitimate sexual and bodily expression. Thomas (2018), in an analysis of young women's self-reported "dilemmas with nude photographs" (p. 192), found that young women experience multiple pressures to sext and tend to see themselves as "reactors" rather than "agents" (p. 203). They privileged young men's desires and wants, and tended to criticise themselves and other young women rather than young men. They struggled with saying no, and Thomas (2018) suggests they lack the tools and resources to navigate youth sexting culture.

While Thomas (2018) notes that some young women likely consent to sexting and do not experience it as a dilemma, there is a need here for a narrative of rights around youth sexting (Albury 2017; Dobson 2018). García-Gómez (2016) found that teenage young women can challenge the idea that sexting is a problem through constructions of agency, knowingness, and control. However, he also found that this was tied up with objectification and casual sexting, which bumped up against more traditional narratives of female passivity and submitting to male desire in relationships. Moving away from a victimhood vs. empowerment binary requires what Dobson (2018) terms "positive sexual rights" (p. 2) in which emphasis 
shifts from the individual to the collective. She suggests that it is necessary to explore how "[s]tructures of inequality mean that some people are positioned as more easily and obviously the recipients of ethical and consensual treatment, while some are structurally more vulnerable to unethical treatment, abuse and limited opportunities for meaningful consent" (ibid: 12, emphasis in original).

The goal should, Dobson and Ringrose (2015) argue, be to engender a digital sexual ethics, in which young people are encouraged to critically deconstruct harmful practices and individualistic tendencies toward victim blaming and social shaming. Albury (2016) suggests that it is about promoting "sexual citizenship" (p. 214), in which the focus is on youth sexual culture itself and how young people operate and make decisions from an ethical perspective. She argues that sexual citizenship — or rights - is about participation as much as protection; rights, therefore, "to do" (ibid: 218) and "to consent" (ibid: 221) (also see Karaian and Van Meyl 2015). She advocates a reorientation away from assumptions that sexting is always about bullying, risk, self-objectification, and self-exploitation, to the varied ways that young people practice sexual and bodily self-expression. Albury (2017) questions how sexting pedagogy could extend digital sexual rights and challenge shame, gender norms, and the normalisation of harm. Given that harmful practices are shaped by youth cultural meanings and norms, she asks:

What if being known as 'someone who gossips, and shares sexual images without consent' was the more shameful identity and was presented to young people as such? What if they were cautioned that inappropriate gossip and non-consensual picture sharing was a violation of others' rights, that it would potentially damage their 'reputation' and future employability? In this context, positive rights to self-expression (such as those identified by Gillespie 2013) would take precedence over negative rights. (ibid: 722).

In this article, I aim to show how harmful sexting practices were predicated upon a denial of rights and how this means, as Albury $(2016,2017)$ and Dobson (2018) suggest, that protection and rights are inherently intertwined. Addressing privacy violations, non-consensual and unwanted sexting, and victim blaming and bullying requires, therefore, attention to the denial of rights that I found occurred not just within interpersonal sexting contexts but that characterised the broader youth sexting culture I encountered in the study.

\section{Methodology}

The research on which this article is based aimed to explore the social meanings and cultural norms that shaped harmful sexting practices, including breaches of privacy and consent, victim blaming and bullying within young people's peer contexts. The following questions guided the research approach and analysis:

- What are young people's practices and perceptions surrounding sexting, particularly regarding the ethics of sexting in terms of privacy and consent?

- What are the underlying social meanings and cultural norms that shape these practices and perceptions?

- What opportunities are there to intervene to challenge harmful sexting practices?

The research involved qualitative group and one-to-one interviews with 23 young men, 16 young women, and two young people identifying as gender-fluid. All were aged between 14 and 18. I recruited participants from schools and youth clubs across a county in south-east England. All identified as being from a white British or other white European background, perhaps because, gatekeepers explained, the research sites catered to a relatively monocultural youth population (e.g. I did not encounter any black or minority ethnic (BME) young people in the youth clubs and BME students made up a very small proportion of the student population in the schools). Twenty-nine described themselves as heterosexual, five as gay/lesbian, three as bisexual two as pansexual, one as biromantic asexual, and one did not specify. Most reported not having a disability although three stated they had a physical disability, six a mental disability, one a learning disability, and one a sensory disability. All participants gave informed consent to participate in the interviews (with gatekeepers assessing their competency to do so).

I held nine group interviews with between three and seven participants each. The group interviews explored participants' use of technology, meanings, and understandings of the ethics of sexting, and practices and perceptions surrounding sexting. I considered the group interview settings to be participants' "natural habitat" (Frost 2003, p. 134). Groups comprised young people known to one another often as friends or, at least, acquaintances. The interviews were held in private rooms within the research sites, most often common rooms that were made available for the research. The interviews were sites of co-constructed meanings, experiences, and positioning among participants. I was guided by the symbolic interactionist approach to exploring how meaning-making processes are reflexively incorporated into self-concepts, decision-making, and practices at individual, interpersonal, and social levels (see Blumer 1969). Group interviews involve interaction, revealing how individuals create meaning (Onwuegbuzie et al. 2009). Starks and Trinidad (2007) advocate attending to how language and words are used to create meaning, designate social roles, and enact identities. They argue that this illuminates norms, negotiation of interaction, and individual and group identity. I was, therefore, interested 
in how the participants jointly constructed and drew on meanings to position themselves and make decisions.

I then invited participants to a one-to-one interview, and seven interviews were held with four young women and three young men. ${ }^{1}$ These interviews were a two-way conversation in which participants shared personal beliefs and experiences of sexting. I considered these interviews to allow "private, unarticulated feelings which might remain concealed in group interview or group discussion... to [find] expression" (Griffiths 1984, p. 515). One-to-one interviews can reveal how individuals interpret their experiences, incorporate meaning into their self-concepts and identities, and modify and challenge meaning (e.g. Charmaz 1995; Faccio et al. 2013, 2014).

Interviews were audio-recorded, transcribed, and uploaded into NVivo for analysis. I was guided by the grounded theory approach to analysis with the aim of foregrounding the participants' perspectives and how they produced meaning with their peer contexts. Charmaz (2014) describes grounded theory as building a theory from successive stages of analysis, in which participants' experiences are understood in abstract terms. She argues that the aim of grounded theory is to move analysis from description to explanation. I adopted Strauss and Corbin's (1998) approach to analysis. I engaged in close reading of the transcripts, noting elements that caught my attention and seemed important to participants. I coded lineby-line, and codes were initially descriptive. I then engaged in interpretive coding, in which I explored how participants spoke about different issues and what was being constructed to develop categories and themes.

Grounded theory enabled me to identify how participants gave meaning to sexting and how these meanings shaped their practices and perceptions around risk and harm. Analysing and interpreting their accounts in terms of wider theorising and research then enabled me to explore the ways in which social shaming and a denial of rights infused their sociocultural constructions of sexting. I was subsequently able to draw out how protection from harm requires an articulation of rights for individuals but through collectivist orientations that account for the role of the broader peer culture in giving meaning to sexting and providing a facilitating context to harmful sexting practices. In this sense, Charmaz (1990) conceives of the researcher as active and as shaping the process and product of research. She argues that data and theories are not "discovered"; researchers are part of discovering them, so "... any theoretical rendering others an interpretive portrayal of the studied world, not an exact picture of it" (ibid: 10, emphasis in original). My conclusions about participants' youth sexting culture were based on my interpretation of their accounts in terms of equality, social justice, and rights.

\footnotetext{
${ }^{1}$ These interviews were held with young people at the school. Gatekeepers at the youth clubs did not consent to young people being interviewed in a one-toone setting.
}

The study and methodology received approval from the Faculty of Arts and Social Sciences Ethics Committee at the University of Surrey.

\section{Findings}

The analysis revealed that most of the participants were risk averse, individualistic, and moralising in their constructions of sexting. They were concerned particularly about reputational damage. Their constructions of sexting were shaped by meanings and norms surrounding gender and sexuality, which worked to delegitimise and deny rights to bodily and sexual expression. These meanings and norms facilitated social shaming, and contextualised harmful sexting practices in terms of breaches of privacy and consent. The analysis revealed that participants as a collective gave meaning to sexting, regardless of the particular position individuals adopted in terms of whether they chose to sext or not. The taken-for-granted nature of risk and harm in youth sexting culture legitimised and normalised victim blaming and bullying. Some participants challenged such practices and supported more positive forms of bystander intervention; however, there was a lack of appreciation of the role of the peer group in producing the sociocultural context that gave rise to risk.

\section{Sexting as Stupid and Risky}

Most participants described sharing personal sexual images as stupid and risky. They constructed the body as something private and felt that sexting risks exposure beyond the intended recipient, which they perceived could have damaging short- and long-term reputational consequences (Setty 2018b). Chris (16, M), for example, stated that he was concerned that any image could "be put on the internet and then I will look back for the rest of my life; that's the risk". These participants conceived of sexting images as "a permanent record of something that you probably wouldn't want most people to see... [so] don't do it" (Ben, 16, M). Most participants believed that there are few potential benefits to sexting and the risk, therefore, is not worth it:

I: In terms of this stuff, like do you hear about people doing it?

Tee (17, non-binary): You're just like why?

Kate (17, F): You're at school, somebody's gonna find out; the whole school is gonna find out about this thing. Tee: What's happened at my school, someone's sent a girl a nude, a bloke's sent a girl a nude.

Kate: And she goes and tells everyone.

Tee: It's got round the school and everyone is just like, why? They're just showing you, the people getting the photo. 
Kate: And then the whole school finds out.

Tee: And the people thought it was priva te.

Most participants were, resultantly, at least somewhat favourable to abstinence-based education and efforts to deter young people from sexting. Becky $(15, F)$ felt that such approaches help in "showing that it's wrong". Some of these participants could, somewhat, "get where they [adults] are coming from" (Chris and Andy, both 16, M) when they warn young people about the risks of sexting. They conceived of young people as being vulnerable and in need of guidance and protection by adults. Ben $(16, \mathrm{M})$ felt that "until you actually learn what to do and have understanding, having your parents there to limit what you do actually sounds like a very good thing...". As these extracts suggests, many participants predominantly perceived there to be something inherently wrong and inappropriate about sexting. They may have been recreating wider risk and deviance narratives in their positioning of themselves as smart and responsible (Crofts et al. 2015; De Ridder 2017, 2018). Their discussions also suggested that something deep was at stake in terms of the meaning of and status projected through sexting.

\section{Sexting as Shameful and Stigmatising}

As well as describing sexting as stupid, several participants used terms such as "disgusting" (e.g. Sam, 15, F) and "revolting" (Adam, 15, M). The risks - in terms of the reputational damage that may result from being exposed as a sexter-arose from the shameful and stigmatising status that these participants felt is projected through sexting (see De Ridder 2017, 2018). The particular status that sexting projects was made meaningful through norms and expectations surrounding gender and sexuality. Similarly to previous research (e.g. Ringrose et al. 2012), several participants described young women who sext as "sluts", "needy", and "attention-seekers" (see Setty 2018a). As I discuss below, there was, as previous research suggests, the potential for young men to seek social capital through sexting; however, some participants were also critical of young men who sext. They described them as "creepy" (John, 17, M), "desperate" (Andy, 16, M), and "weird" (Chris, 16, M).

These descriptions were based on participants' constructions of approved forms of feminine and masculine sexual and bodily expression. Many of the participants conceived of young women as transgressing feminine sexual norms through sexting (see De Ridder 2018). Their sexual and bodily self-expression was attributed to their desire for attention and affirmation from young men, and their "low self-esteem" (Rosie, 17, F) and "self-worth" (Naomi, 15, F) (see Setty 2018a; Hasinoff 2015). Most participants tended, therefore, to accord little agency or legitimacy to young women who sext (see Dobson and Ringrose 2015). While they were judgmental about female sexual and bodily expression through sexting, they felt young women could avoid too much shaming if "that's the first photo they've ever sent" (Adam, $15, \mathrm{M})$ and they do not have too much of pre-existing a "slut" reputation. Young men who sext, meanwhile, were described by some as attempting to project "dominance" (Bond, 18, M) through sexting. On the face of it, participants felt that "if you're a fuck girl or a slag, you're treated bad[ly]. If you're a boy, if you're a fuck boy you get lad points..." (Becky, 15, F). Most participants normalised masculine sexuality and believed that young men who sext were motivated by "sexual attraction" (John, 17, M). Resultantly, they accorded them with greater legitimacy in their sexting practices.

Several participants felt that the ability for young men to accrue social capital through sexting was dependent upon how "confident" (Tom, 17, M) they were perceived to be in the peer group. More popular young men-i.e. those considered more attractive and socially accomplished - were seen as being able to project a desirable status through sexting, particularly, as I discuss below, through obtaining and distributing the images of young women. Producing and sharing personal sexual images of their own, however, was more risky, with Ling $(17, \mathrm{M})$ stating that he feels that this would not "be very effective" because "girls don't actually like this". Such practices could, therefore, project a creepy or desperate status. Again, however, this was more for young men who lacked status in the peer group to begin with. Some participants also showed ambivalence about young men who seek social capital through the images of young women. Brian $(17, \mathrm{M})$ described them as "not necessarily the smartest ones". Others felt it projects a "basic" (Bond, 18, M) form of masculinity based on the objectification of women in male peer groups. It seemed, therefore, that the meanings some participants constructed of sexting were shaped by an interaction between sexting practices, the pre-existing status of those involved, and their self-concepts and social positioning regarding gendered sociocultural norms and expectations (see Crofts et al. 2015).

\section{Privacy Violations}

As stated above, the majority of participants were concerned about the potential for unauthorised distribution of personal sexual images. The designation of sexting as potentially shameful, more so for young women but also for some young men (Setty 2018a, 2019), meant that exposure could be "embarrassing" (Gary, 15, M). While this risk was normalised and taken-for-granted (Setty 2018b), it was apparent that unauthorised distribution is the result of decisions taken by individuals. Andy (16, M), for example, stated that "the person who shared it had the choice to... share it or just keep it secret". Both the choice to distribute and the impacts of distribution on individuals reflected and reinforced constructs of 
gender and sexuality, and young people's status within peer culture. Some participants felt that individuals distribute images for purposes of "humiliation" (Chris, 16, M), "revenge" (Simon, 15, M), "spite" or to "bully" (Leo, 17, M), and to gain esteem and status within the peer group (see Crofts et al. 2015). The power of the images to achieve these aims was, it seemed, a result of tendency of many of the participants to construct producing and appearing in sexual images as shameful.

Most participants perceived young men as benefiting from this dynamic to a greater extent than young women. The positioning of young women as passive objects of male desire, with little legitimate, agentic sexuality of their own, meant many participants felt their images could be distributed around the peer group for the purposes of male pleasure and peer bonding. Becky $(15, \mathrm{~F})$ described how "boys... will screenshot and will show all their mates... and it escalates, it gets bigger and bigger...". The majority of participants perceived such young men to be "treated as a hero" (Bob, $17, \mathrm{M}$ ), and one group of young men recounted instances in which "there will be a lot of boys like trying to surround him and trying to find the picture" (Simon, 15, M). The construction of sexually expressive young women as sluts meant that not only were their images distributed for purposes of objectification, but also to shame and ostracise them as disgusting and lowly. Some participants described a "mob rule"-type reaction (Becky, 15, F), in which the violation of norms and standards projected through sexting attracted attention and, as I discuss below, bullying and abuse in the peer group. Young men were not immune to unauthorised distribution, however, despite most participants feeling that "girls don't really get off on a picture of a boy" (John, 17, M). Some participants felt that unauthorised distribution of images of young men tended to occur more to humiliate those considered desperate or creepy in their practices (see Setty 2019).

Several participants discussed how the decision to distribute a personal sexual image was also related to and impacted by the social position of the subject and the distributor in the peer group. Young people that occupied a position of power within the peer hierarchy were believed to "make... decision[s] [about] whether they think it [sexting] was right or not... [and] other people will follow" (Becky, 15, F). Some participants considered it untenable for a less popular person to distribute or cast judgment on the image of a more popular person, while images of less popular people can become property of the peer group to do with as they wish. Two young women discussed how unauthorised distribution would have different impacts on each of them. They said that one was more popular and one was less popular, and the less popular young woman felt that she would get a lot more "judgment" for sexting (Skye-Rose, 16, F). Some participants felt that less popular young people can become "victims" (Naomi, 15, F) and targets of abuse. Further, they considered the dynamic between the sexters to be important. Kyle $(16, \mathrm{M})$, for example, recounted an incident when a young man was revealed to be sexting with a young woman that "no one really likes... [so] he got a lot of hate for it". Participants' discussions revealed, therefore, how norms and meanings, and peer group dynamics and hierarchies underpinned both decisions to distribute images and the peer reaction to those involved.

\section{Non-consensual Sexting}

Participants likewise constructed unwanted and pressured sexting in terms of gendered sociocultural norms and meanings. As I have discussed elsewhere, many participants felt that young women can experience pressure to engage in sexting in response to the demands and perceived desires of young men (Setty 2018a). Participants' delegitimisation of young women's sexuality and construction of young women as passive in sexual matters worked to normalise and naturalise this gendered pressure. Young men were seen as having uncontrollable sex drives that compelled them to pursue and, therefore, pressure young women. Bond $(18, \mathrm{M})$, for example, stated that "a lot of the time, you're thinking with a different part of your body... the blood's somewhere else". Several participants constructed young men as the sexual beneficiaries of sexting and conceived of young women as not seeking or gaining sexual pleasure from the practice. Skye-Rose $(16, \mathrm{~F})$, for example, who recounted having engaged in sexting, felt that she gets little sexual pleasure from viewing images of young men. Her interest was more in the accomplishment of arousing her sexting partners and the potential for physical sexual activity later on, as she felt that "females can only really get pleasure... in real life". While challenging the notion that young women are entirely sexually passive, her comments reflected the perceptions held by other participants: essentially that young women sext to please young men.

Most participants believed that pressured sexting results from this combination of young men's sexual drives and desires, and young women's difficulties saying on. These difficulties were attributed to young women's low self-esteem and desire for attention and affirmation from young men. Some participants perceived these processes to be intensified when there is a status differential between the young man and young woman. Naomi $(15, \mathrm{~F})$, for example, felt that when "more popular boys" request images from "less popular girls", it can be very flattering and young women, herself included, can feel compelled to respond to keep the young man's interest. Naomi recounted having felt "used" by high status young men, who she believed saw her as "easier" to obtain images from due to her lower status and, therefore, increased willingness to comply with their requests. 
Several participants also discussed unsolicited image-sharing, in which young men send explicit images to young women without warning. ${ }^{2}$ Bond $(18, \mathrm{M})$ recounted having sent unsolicited images to young women when he was younger and explained that he conceptualised it as "trying his luck". While acknowledging that most young women are unlikely to be interested, he felt that they could just ignore him and it was a quick and easy way of searching out the "dodgy" type of girl who would want to sext. While he was critical of his younger self for engaging in non-consensual sexting, he stated that at the time he did not see it as a problem and he, along with the other young men in his group, laughed about how young men will expose themselves explicitly to young women.

B ond: I could send it and that person could want it and it cuts out the all the boring work, if you know what I mean, I mean you can get straight down to the nitty gritty...

James (16, M): Cut to the chase.

Bob (17, M): Skip to the good bit.

Bond: I mean you don't have to waste your time, you both know what's going on and... I can understand why, it does make sense. You're laying out on the table, I want this, are you interested? No, that's fine, I'll go. Yes, brilliant, let's go.

These practices involve a discounting of the rights of young women to be given a choice and opportunity for meaningful consent. Of more interest to Bond-at least when he was younger - was his pursuit of young women, albeit young women he denigrated as "dodgy". Ultimately, young women were disadvantaged and denied rights here on two levels. Bond privileged his own sexual drives and desires, and the value to him of skipping the "boring work" of sex and relationships over the rights of young women. He also valued their images for the pleasure it brought him, while attributing shameful and stigmatising labels to the young women themselves (see Lippman and Cambell 2014). While Bond was looking for the sexually willing young woman who would respond affirmatively to his advances - thus according some sexuality to them - he delegitimised them with his use of the label "dodgy". Many of the young women were critical of young men who send unsolicited images for the breach of consent it represents and the sense of unease for, essentially, being targeted as one of the "dodgy" young women who may respond affirmatively. Some young men, meanwhile, were critical of unsolicited image-sharing but more emphasised its likely ineffectiveness in terms of sexual accomplishment and the "desperation" (Chris, 16, M) it conveys on the part of young men. As such, understandings and constructions of

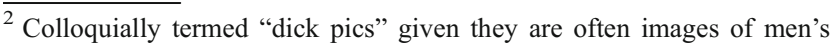
penises.
}

non-consensual sexting were shaped by perceptions and expectations of feminine and masculine sexuality and the dynamics between young men and women.

\section{Victim Blaming and Bullying}

The majority of participants were, somewhat, critical of violations of privacy and consent in youth sexting culture. The sociocultural meanings and norms that shaped such practices were, however, normalised to the extent of appearing invisible (see Mishna et al. 2018). This meant that most participants engaged in victim blaming and, because they conceived of sexting as projecting a negative status, justified social shaming, and bullying. Those who perpetrate harm - either violations of privacy and consent-were less at the forefront of many of the participants' minds. The peer focus was, instead, more on the perceived wrongs of the subject of the images. Some felt that the gossip and rumours that rapidly spread about the subject in the event of unauthorised distribution means the distributor almost disappears from view:

I: What about the person who distributes the image? Does anybody react badly to the person who's leaked it? Lexi (14, non-binary): It's quite hard to find the person that distributed the image, like if it's gone out like a spiral, like multiplied and spread.

Jessie (15, F): Yeah usually by the time you've heard it, you get like oh my goodness, where did you hear that from, I heard it from [name], [name] heard it from [name], [name] heard it from [name], [name] heard it from [name], [name] heard it from [name], like it goes back a really long way.

Some, however, conceptualised unauthorised distribution as representing a violation of trust on the part of the distributor. Referring to consensual (rather than unsolicited) image-sharing, they believed that the subject of the image had placed trust in the intended recipient by sending them the image; however, this trust was described as "stupid" (Gary, 15, M; Dan, 15, M). Ben $(16, M)$, referring to a sexting scenario in which a young man distributes an image of a young woman, said that "[t]hey're both stupid. The girl was stupid; the guy was a dick". Despite being somewhat critical of distributors, most participants ultimately, however, believed that individuals "just have to take control of what you can, so if you don't send the image, then it can't be distributed" (Ling, 16, M). The trust was conceived of as misplaced and, therefore, a "mistake" or the "fault" (Sam, 15, F) of the subject. Furthermore, while many of the participants somewhat grappled with who they felt was responsible, their discussions were individualised. Their criticism of distributors was framed in terms of the individual not being "nice enough" to keep it private (Lexi, 14, non-binary). There was little attention to 
the broader sociocultural context to unauthorised distribution, in which, for example, distributors may be motivated by the social capital they anticipate accruing.

Some participants discussed how victims of unauthorised distribution can be targeted with "horrible" (Brian, 17, M) bullying and abuse when exposed as sexters. Becky $(15, \mathrm{~F})$ stated that they can be "bullied and laughed at, and like ridiculed for it". While some felt that bullying can be unpleasant for those on the receiving end, many showed little sympathy. Sam (15, F), Brian and Becky's fellow participant, stated that this is "their own fault". Adam $(15, \mathrm{M})$, meanwhile, stated "who cares, like don't do it again. You've made a mistake, like you shouldn't make the same mistake again". The characterisation of sexting as a mistake that conveys something negative on the part of the subject worked to justify social shaming and bullying within the peer group (see De Ridder 2018).

Some participants likewise showed little sympathy for experiences of non-consensual sexting. Ling $(16, \mathrm{M})$, for example, maintained that:

Maybe you were pressured, maybe you were not, but you sent an image, okay, and now that [unauthorised distribution] might happen. So even if you are the victim of this situation, it doesn't make a difference, because if you were forced into it, if you agree, if you willingly did it, you have to understand that the risk is exactly the same, at some point you have to take ownership of that, and say that I have control of this situation.

The materiality of mobile phones and other forms of technology also meant that some participants expressed little sympathy for those experiencing non-consensual sexting. ${ }^{3}$ The distance technology implies between sender and receiver meant that they struggled to understand how a person could feel compelled to sext, and they felt that it was easy to just say no. Tee (17, non-binary) and Kate (17, F) discussed how individuals should just "walk away" if they experience pressure in digital spaces:

Kate: ...some people are so stupid. If you don't send me one I'm gonna break up with you and they like them so much it probably hurts their feelings, even though, if I got that I'd be like, we're over.

Tee: If you're only there for the picture, surely, they'll feel bad. People have got to realise that if people are like, I'm gonna break up with you, it's like, go ahead.

Kate: I'd be like, bye.

Tee: I'm gonna send you a picture of me and you don't care about me enough to not have these pictures, then you're not really good material there.

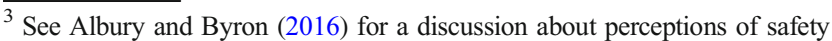
and digital sexual communication.
}

The lack of legitimacy and rights accorded to young women in sexual matters meant that most participants placed responsibility on them to be attuned to the risks of sexting. Several participants spoke about how young women should be mindful of what pressure suggests about young men. John $(17, M)$, for example stated that "if the boys says, oh if you don't send it, I'm not gonna be your boyfriend, then he's a scumbag anyway and you shouldn't be with him" (John, 17, M). Likewise, many participants felt that the best response to unsolicited image-sharing was to "ignore" the young men who send the images and "say, if I don't talk about it... it won't happen again" (Marley, 17, F). Lacking in most of the participants' discussions about violations of privacy and consent was any critical engagement with the wider sociocultural context to such practices.

\section{Bystander Intervention}

Some participants were critical of bullying and abuse in the peer group surrounding sexting. They articulated a desire for a kinder, and more compassionate and empathetic peer culture. However, their support for a more positive model of bystander intervention was, at times, predicated upon the same sociocultural norms and meanings that underpinned harmful sexting practices. Consequently, such bystander intervention seemed unlikely to challenge the broader context of risk and harm in youth sexting culture.

Some of the young women felt that because sharing an image of yourself (as long as not unsolicited) - from their perspective - is about trust and intimacy, sexting subjects should not be judged or treated harshly. They particularly felt that if young women experienced pressure to sext then they should not be blamed, because, ultimately, all they have done is given young men what they wanted. Participants were generally more sympathetic to those who, Becky (15, F) stated, sexted as a result of "pressure" rather than "free will". Brian (17, M) said that it can be "hard to say no if you either love them or you just can't say no...". These sorts of sexters - who were predominantly assumed to be young women - took on an almost ideal victim status (Christie 1986) compared with the "dodgy attention-seekers" who sext willingly and who attracted more opprobrium. In this sense, participants' displays of sympathy and compassion were shaped by gendered norms and meanings about sexting practices. A group of young women spoke about "reach[ing] out" (Charlie, F) to support victims of unauthorised distribution. However, they couched this support in terms of stereotypical assumptions about the nature of young women's engagement in sexting:

Marley (16, F): She probably needs a talking to, like why did you do this? ...is everything ok? ...did you 
do this because you wanted to? ...check that everything is okay with it.

Lily (17, F): ...check she wasn't pressured. That could make the boy in even more trouble like if he pressured her to send them on.

Marley: ... if she was doing it because she had low selfconfidence and she wanted to be... told she was pretty, she might need a bit of help...

While some participants characterised sexting as being about trust and intimacy, and thus potentially deserving of rights, these accounts were infused with assumptions about gender and sexuality. This meant that rights were deemphasised in favour of forms of bystander intervention in the event of unauthorised distribution that reflected and reinforced the social meanings and cultural norms that underpinned harmful practices. I asked the young women above whether they would apply the same reasoning to young men and gendered assumptions similarly shaped their discussions:

I: And what about if it was the other way around, would the same checks need to be made if it was a guy who sent the picture, like with consent and stuff?

Lily: Technically yeah, but I don't think they would be.

If it's a guy, he's more brushed off because he's not seen as weak... I know that's not what it's really like -

Marley: To be fair though, it kind of depends on the guy... if you've got a little... this will sound bad, but a nerdy sort of guy -

Lily: Yeah.

Marley: ... you're probably gonna more be like -

Lily: This is odd for you.

Marley: Yeah, like were you pressured into this? Or if you've got... a jockey guy, you'll be like, yeah, this is just like you.

Models of bystander intervention that do not challenge the broader context of harmful practices risk reinforcing the very practices they seek to address. A group of young women spoke about how individuals may pose as supportive bystanders but do so disingenuously with the view to extract further potentially damaging information from the victim. The value of sexting within the peer group, in terms of how it reflects and reinforces gendered peer group dynamics and hierarchies, may promote such practices. Likewise, the interplay of gender with how young people may react to sexting incidents may create further division and resentment. Becky $(15, \mathrm{~F})$ and $\operatorname{Sam}(15, \mathrm{~F})$, for example, described their school as "sexist" because young women who experience unauthorised distribution are seen as "victimised" and provided with support, while young men are conceived of as not requiring support. Participants displayed ambivalence about this, however, with several young men arguing that young women "make a drama" and do not let the peer group reaction run its course. John $(17, \mathrm{M})$, for example, said that “... that's where girls handle it wrong... if they just were to brush it off their shoulders and say I don't care, boys and girls would just be like, oh, I can't really take the mick out of them now, because they don't care". Some young men maintained that young women should behave more like young men so as to mitigate any negative reaction they face. Participants did not acknowledge that perhaps young women appear more upset and, potentially, receive more support because of the greater meaning attached to their sexting practices and, therefore, the more severe social reaction they face. This again demonstrates a lack of acknowledgment as to the role of the peer collective in giving rise to risk and harm.

\section{Sex(ting) Education}

Some participants challenged the idea that sexting is an inherently wrong and deviant practice for young people. They articulated a desire for a form sex and relationships education in which sexting is recognised as a "valid expressive choice, notwithstanding our complex cultural context" (Karaian and Van Meyl 2015, p. 20). Charlie (15, F), for example, challenged the assumption that sexting is always harmful and stated that she wanted education around "stay[ing] safe", in which adults "accept that it's going to happen". Charlie's position was, however, rare. Other young women were more ambivalent and their comments tapped into the challenging cultural context within which they are operating. These young women wanted more recognition of the competing pressures and demands they are under in youth sexting culture. Ultimately, however, they reproduced narratives of regret and shame. Naomi (15, F), for example, wanted more input from similarly situated peers who can tell their stories:

Yeah, I don't know... what would have made me not do it, 'cause... I can't think back to it. But I guess... someone talking to me... about the things that could happen... have happened, rather than... dramatic sort of things, like, oh, it's gonna get out and everyone's gonna see it. More about how people feel when their exposed that much... being told that might've kinda affected me and made me not do it.

Similarly, Skye-rose $(16, F)$ wanted more support. She weighed up her experiences of pleasurable sexting with the belief that she could have been deterred had "someone come in with their story, this is what happened, I felt really ashamed of myself afterwards, like I felt, then I would've been like, shit yeah". Regardless of whether these approaches would have meant young women like Naomi and Skye-Rose would not have sexted, it seemed that experiences of sexting were made 
sense of in terms of gendered narratives of risk, regret, and shame (see Karaian 2014).

There was a tendency among many of the participants who said that they had not engaged in sexting personally to other the need for interventions and education. While they were, in the abstract, supportive of abstinence-based education and legal prohibition of sexting, this was for young people that they felt were reckless and immature. When talking about what they want in terms of education and support, they were more critical. They criticised adults for - in their view — missing the point, generalising unfairly about young people, and being too alarmist and fearful. While they readily judged one another for sexting, they were concerned about the risks of being judged and punished by adults. However, the tendency to position themselves as "older and wiser" in terms of having insight into the risks and harms of sexting (Adam, 15, M) meant that they did not necessarily advocate an approach to sexting based upon rights and ethical conduct. More, they said that they wanted something different because they would never be that "stupid".

\section{Discussion}

The analysis has revealed how participants made sexting meaningful through social meanings and cultural norms relating to gender and sexuality. Sexting was a significant cultural phenomenon within participants' peer contexts due to its power to portray and project status and meaning about those involved (Crofts et al. 2015). Participants made sense of unauthorised distribution of sexual images and non-consensual and unwanted sexting in terms of gendered sociocultural meanings and norms. These meanings and norms were taken-for-granted and normalised to the extent that participants conceived of harmful sexting practices as to be expected and up to individuals to anticipate and avoid. Many participants engaged, therefore, in victim blaming - and, for some, personal narratives of shame and regret — of those who share images and encounter harm. However, it was apparent that participants' co-constructed meanings and norms provided a facilitating context for these harmful sexting practices. While most participants sought to distance themselves from sexting and positioned themselves as sensibly and maturely abstaining from sexting, they did not recognise the role they play as the powerful audience in legitimising particular courses of conduct and practice in youth sexting culture (De Ridder 2017, 2018; Hasinoff 2015; Powell 2010; Symons et al. 2018). They too were also learning about gender and sexuality through youth sexting culture, regardless of their personal involvement in the practice (Bailey and Mouna 2011).

It was the broader youth cultural context constructed in the interviews that ultimately determined which images were distributed, who experienced pressured and unwanted sexting, and who was blamed and who was absolved for harmful practices. Underpinning these processes was, essentially, a denial of rights. The shame and the stigma resulting from unauthorised distribution combined with the social capital accorded to those who distribute such images involved a denial of rights to those who appear in the images to bodily and sexual integrity and privacy. Non-consensual and unwanted sexting likewise involved a denial of rights to meaningful choice. Many of the participants' constructions of privacy violations and non-consensual and unwanted sexting was shaped more by their values and expectations around approved masculine and feminine sexuality than the ethicality of such practices. They emphasised the need for young men to avoid looking desperate or creepy when sending unsolicited images or placed responsibility on young women to say no and resist the sexual advances of young men (see Tolman et al. 2015), for example, rather than focusing on the violation of rights entailed in non-consensual sexting.

Participants' roles and responsibilities as the audience or bystanders are, therefore, important to understanding risk and harm in the youth sexting culture I encountered in this study. Most participants tended not to distinguish between sexting contexts in their judgments of sexting actors. Rather, their judgments were shaped by restrictive standards of approved sexual and bodily expression, which interacted with perceptions regarding the pre-existing status and social position of individual sexting actors. The pervasiveness of taken-forgranted gender stereotypes and assumptions meant that even among those advocating a more ethical approach, their constructions remained predicated upon the same norms and meanings that justified and facilitated harmful practices. For example, the demarcation of young women who sext as having "low self-esteem" contributed to the shaming of young women who sext and shaped narratives around bystander intervention. The majority of participants rarely spoke about protection from harm in terms of rights to bodily and sexual expression; rather they either engaged in victim blaming in which individuals were held responsible for anticipating and avoiding risk, or advocated bystander intervention based on stereotypical ideas about responsibility and vulnerability.

Reducing risk and harm in youth sexting culture requires, therefore, an articulation of rights (Albury 2017; Dobson 2018; Dobson and Ringrose 2015). Such an articulation should be collectivist in nature, in that it needs to account for the social and cultural processes that normalise and legitimise harmful practices. As Albury (2017) argues, it is necessary to deconstruct the gender and sexual assumptions and stereotypes that promote shaming. The emphasis should on the re-legitimising of sexuality, in terms of individuals' rights to exercise control over the boundaries of their bodies; to make free, informed, and empowered choices; and to expect support, protection, and justice in the event of harm. If a person has an inviolable right to their body and sexuality, it would, I contend, become less tenable to distribute privately 
produced sexual images for social purposes, to pressure or coerce someone to sext, or to send unsolicited images. In the event of harm, the focus would then be on the responsibilities of the perpetrator rather than the perceived wrongs of the victim (see Albury 2017). Models of bystander intervention in which the peer group refuses to facilitate or support harmful sexting practices in a broad sense require this deconstruction of taken-for-granted meanings and norms, and an articulation of rights (see Hasinoff 2015; Powell 2010).

The current legal and educational context surrounding youth sexting reinforces the notion that risk and harm are inevitable; bodily expression shameful and likely to attract condemnation (from peers, employers, educators, and others); young women as passive and at risk of victimisation; young men as naturally sexual even predatory; and abstaining from sexting the best way of managing risk and avoiding harm (Dobson and Ringrose 2015; Hasinoff 2015). Rather, what is required is opportunities for young people to critically engage with youth cultural processes and their roles and responsibilities as the audience (see Hasinoff 2015; Powell 2010). Young people could be shown that regardless of their personal choices, they contribute to making sexting meaningful and are undergoing a process of learning through youth sexting culture (see Symons et al. 2018). Consequently, sex and relationships education need not focus on individuals' practices, which may be challenging given the discomfort, caution, and risk aversion that currently predominates in this area (e.g. Lloyd 2018).

Instead, sexting could become a platform for critical learning about relationships, sex, rights, responsibilities, ethics, and justice (Albury et al. 2013). Young people could be asked what they think about sexual and bodily expression in a broad sense, and then guided to explore how risk and harm emerge from a cultural context characterised by stereotypes and inequalities. There could be a possibility here for what Lee et al. (2018) term "inter-generational co-learning" (p. 1) in which adults are positioned less as impartial experts. Instead, the emphasis is on a collaborative approach between adults and young people, in which they come together to rethink social issues and develop solutions. Naezer et al. (2017) suggest that "sexual knowledge building" should replace "sex education" (p. 713). They conceptualise the former as less formal, didactic, and moralising than the latter, and more of a process focused on information, understanding, and contexts of learning. They found that young people vary in terms of the type of information and guidance they want and feel they need from sex and relationships education, and such education should, therefore, be more youth-focused. These approaches may help address perceptions that adults are out-of-touch and judgmental. I would suggest that imperative is challenging the othering and moral distancing that I uncovered in my research (see De Ridder 2017, 2018). Young people should be encouraged to look beyond sexting as individualised — but socially meaningful and impactful - micro-interactions to how, as a cultural phenomenon, it reflects and reinforces broader social inequalities, power imbalances, and injustices that, ultimately, impact upon them all.

\section{Limitations and Avenues for Future Research}

The analysis presented here is based on in-depth qualitative research with a small sample of ethnically homogenous young people. As such, the findings represent the situated meaningmaking processes of these particular young people. As youth cultural perspectives likely vary between young people, further research that explores how young people construct meaning and how meaning works to provide a facilitating context to harmful sexting practices, as well as the power dynamics and social inequalities within this context, would be of value. Further research could also explore young people's perspectives on sexting education (see Jørgensen et al. 2018) and how a rightsbased approach could practically be created and promoted.

\section{Conclusion}

Youth sexting should not be understood as inherently a form of bullying, but as the having the potential to involve or lead to bullying for particular individuals (Dake et al. 2012; Lee and Crofts 2015). This may take the form of situated individual and interpersonal practices of violations of privacy and consent, as well as broader social processes of victim blaming, shaming, harassment, and abuse (Angrove 2015; Ringrose et al. 2013; Shariff and DeMartini 2015). This article has shown how participants constructed these practices and behaviours in terms of gender and sexual stereotypes and inequalities, and peer group power dynamics and hierarchies (see Mishna et al. 2018). It is imperative that sex and relationships education attends to this broader youth cultural context, emphasises the roles and responsibilities of bystanders, and encourages a collectivist digital sexual ethics based upon both rights to one's body and freedom from harm (Albury 2017; Dobson and Ringrose 2015).

Funding Information This research was funded by the Sociology Department at the University of Surrey through a departmental doctoral studentship.

\section{Compliance with Ethical Standards}

Conflict of Interest The author declares that there are no conflicts of interest.

Open Access This article is distributed under the terms of the Creative Commons Attribution 4.0 International License (http:// creativecommons.org/licenses/by/4.0/), which permits unrestricted use, distribution, and reproduction in any medium, provided you give appropriate credit to the original author(s) and the source, provide a link to the Creative Commons license, and indicate if changes were made. 


\section{References}

Albury, K. (2013). Young people, media and sexual learning: rethinking representation. Sex Education, 13(1), 32-44.

Albury, K. (2016). Politics of sexting revisited. In A. McCosker, S. Vivienne, \& A. Johns (Eds.), Negotiating digital citizenship: control, contest and culture (pp. 213-230). London: Rowman and Littlefield.

Albury, K. (2017). Just because it's public doesn't mean it's any of your business: adults' and children's sexual rights in digitally mediated spaces. New Media \& Society, 19(5), 713-725.

Albury, K., \& Byron, P. (2016). Safe on my phone? Same-sex attracted young people's negotiations of intimacy, visibility, and risk on digital hook up apps. Social Media and Society, 16(4), 1-10.

Albury, K., Crawford, K., Bryon, P., \& Matthews, B. (2013). Young people and sexting in Australia: ethics, representation and the law, final report. Sydney: Australian Research Centre for Creative Industries and Innovation, University of New South Wales. Retrieved from: https://eprints.qut.edu.au/109550/

Angelides, S. (2013). Technology, hormones and stupidity: the affective politics of teenage sexting. Sexualities, 16(5/6), 665-689.

Angrove, G. (2015). "She's such a slut!": the sexualised cyberbullying of teen girls and the education law response. In J. Bailey \& V. Steeves (Eds.), eGirls, eCitizens: putting technology theory, policy \& education into dialogue with girls' and young women's voices ( $\mathrm{p}$. 307.336). Ottawa: University of Ottawa Press.

Bailey, J., \& Mouna, H. (2011). The gendered dimensions of sexting: assessing the applicability of Canada's child pornography provision. Canadian Journal of Women and the Law, 23(2), 405-441.

Blumer, H. (1969). Symbolic interactionism: perspective and method. New Jersey: Prentice-Hall Inc..

Burén, J., \& Lunde, C. (2018). Sexting among adolescents: a nuanced and gendered online challenge for young people. Computers in Human Behavior, 85, 210-217.

Charmaz, K. (1990). Discovering chronic illness: using grounded theory. Social Science and Medicine, 30(11), 1161-1172.

Charmaz, K. (1995). The body, identity and self: adapting to impairment. The Sociological Quarterly, 36(4), 657-680.

Charmaz, K. (2014). Constructing grounded theory (2nd ed.). London: Sage Publications Ltd..

Christie, N. (1986). The ideal victim. In E. A. Fattah (Ed.), From crime policy to victim policy (pp. 17-30). Hampshire: The Macmillan Press Ltd..

Clancy, E. M., Klettke, B., \& Hallford, D. J. (2019). The dark side of sexting - factors predicting the dissemination of sexts. Computers in Human Behavior, 92, 266-272.

Cooper, K., Quayle, E., Jonsson, L., \& Svedin, C. G. (2016). Adolescents and self-taken sexual images: a review of the literature. Computers in Human Behavior, 55, 706-716.

Coy, M., Kelly, L., Elvines, F., Garner, M., \& Kanyeredzi, A. (2013). "Sex without consent, I suppose that is rape": how young people in England understand sexual consent. London: Office of the Children's Commissioner Retrieved from: https://cwasu.org/wpcontent/uploads/2016/07/CONSENT-REPORT-EXEC-SUM.pdf.

Crofts, T., Lee, M., McGovern, A., \& Milivojevic, S. (2015). Sexting and young people. Basingstoke and New York: Palgrave Macmillan.

Dake, J. A., Price, J. H., Maziarz, L., \& Ward, B. (2012). Prevalence and correlates of sexting behavior in adolescents. American Journal of Sexuality Education, 7(1), 1-15.

De Ridder, S. (2017). Social media and young people's sexualities: values, norms and battlegrounds. Social Media and Society. https://doi.org/10.1177/2056305117738992.

De Ridder, S. (2018). Sexting as sexual stigma: the paradox of sexual self-representation in digital youth cultures. European Journal of Cultural Studies. https://doi.org/10.1177/1367549418810080.
Dobson, A. S., \& Ringrose, J. (2015). Sext education: pedagogies of sex, gender and shame in the schoolyards of Tagged and Exposed. Sex Education, 16(1), 8-21.

Dobson, A. S. (2018). Sexting, intimate and sexual media practices, and social justice. In A. S. Dobson, B. Robards, \& N. Carah (Eds.), Digital intimate publics and social media (pp. 93-110). Palgrave Macmillan.

Döring, N. (2014). Consensual sexting among adolescents: risk prevention through abstinence education or safer sexting? Cyberpsychology: Journal of Psychosocial Research on Cyberspace, 8(1), 9 .

Draper, N. R. A. (2012). Is your teen at risk? Discourses of adolescent sexting in United States television news. Journal of Children and Media, 6(2), 221-236.

Department for Education (2018). Relationships education, relationships and sex education, and health education. Retrieved from: https:// consult.education.gov.uk/pshe/relationships-education-rse-healtheducation/. Accessed 25 July 2018

Faccio, E., Bordin, E., \& Cipoletta, S. (2013). Transsexual parenthood and new role assumptions. Culture, Health and Sexuality, 15(9), $1055-1070$.

Faccio, E., Casini, C., \& Cipoletta, S. (2014). Forbidden games: the construction of sexuality and sexual pleasure by BDSM. Culture, Health and Sexuality, 16(7), 752-764.

Frost, L. (2003). Researching young women's bodies: values, dilemmas and contradictions. In A. Bennett, M. Cieslik, \& S. Miles (Eds.), Researching youth (pp. 120-137). Palgrave Macmillan: Hampshire.

García-Gómez, A. (2016). Teen girls and sexual agency: exploring the intrapersonal and intergroup dimensions of sexting. Media, Culture and Society, 39(3), 391-407.

Gillespie, A. (2013). Adolescents, sexting and human rights. Human Rights Review, 13(4), 623-643.

Griffiths, V. (1984). Feminist research and the use of drama. Women's Studies International Forum, 7(5), 511-519.

Harris, A., Davidson, J., Letourneau, E., Paternite, C., \& Miofsky, K. T. (2013). Building a preventative framework to address teen "sexting" behaviours. US: Department of Justice. Retrieved from: https://www.ncjrs.gov/pdffiles1/ojjdp/grants/244001.pdf. Accessed 10 Dec 2014

Hasinoff, A. A. (2015). Sexting panic: rethinking criminalization, priva$c y$, and consent. Urbana, Chicago and Springfield: University of Illinois Press.

Hasinoff, A. A. (2017). Sexting and privacy violations: a case study of sympathy and blame. International Journal of Cyber Criminology, 11(2), 202-217.

Herriot, L., \& Hiseler, L. E. (2015). Documentaries on the sexualization of girls: examining slut-shaming, victim blaming and what's being left off screen. In E. Renold, J. Ringrose, \& R. D. Egan (Eds.), Childhood, sexuality and sexualisation (pp. 289-304). Basingstoke: Palgrave Macmillan.

Jørgensen, C. R., Weckesser, A., Turner, J., \& Wade, A. (2018). Young people's views on sexting education and support needs: findings and recommendations from a UK-based study. Sex Education, 19(1), $25-40$.

Karaian, L. (2014). Policing sexting: responsibilisation, respectability and sexual subjectivity in child protection/crime prevention responses to teenagers' digital sexual expression. Theoretical Criminology, 18(3), 282-299.

Karaian, L., \& Van Meyl, K. (2015). Reframing risqué/risky: queer temporalities, teenage sexting and freedom of expression. Laws, 4, 18 36.

Klettke, B., Hallford, D. J., \& Mellor, D. J. (2014). Sexting prevalence and correlates: a systematic literature review. Clinical Psychology Review, 34(1), 44-53. 
Lee, M., \& Crofts, T. (2015). Gender, pressure, coercion and pleasure: untangling motivations for sexting between young people. British Journal of Criminology, 55(2), 454-473.

Lee, M., Crofts, T., Salter, M., Milivojevic, S., \& McGovern, A. (2013). 'Let's get sexting': risk, power, sex and criminalisation in the moral domain. International Journal for Crime and Justice, 2(1), 35-49.

Lee, N., Hewett, A., Jørgensen, C., Tuener, J., Wade, A., \& Weckesser, A. (2018). Children and sexting: the case for intergenerational co-learning. Childhood, 1-15.

Lippman, J. R., \& Cambell, S. W. (2014). Damned if you do, damned if you don't... If you're a girl: relational and normative contexts of adolescent sexting in the United States. Journal of Children and Media, 8(4), 371-386.

Livingstone, S., \& Third, A. (2017). Children and young people's rights in the digital age: an emerging agenda. New Media \& Society, 19(5), $657-670$.

Lloyd, J. (2018). Abuse through sexual image sharing in schools: response and responsibility. Gender and Education. https://doi.org/ 10.1080/09540253.2018.1513456.

Lunceford, B. (2010). Sex in the digital age: media ecology and Megan's Law. Explorations in Media Ecology, 9(4), 239-244.

Mishna, F., Schwan, K. J., Birze, A., Van Wert, M., Lacombe-Duncan, A., McInroy, L., \& Attar-Schwartz, S. (2018). Gender and sexualised bullying and cyber bullying: spotlighting girls and making boys visible. Youth Society. https://doi.org/10.1177/ $0044118 X 18757150$.

Moran-Ellis, J. (2012). Sexting, intimacy and criminal acts: translating teenage sexualities. In P. Johnson \& D. Dalton (Eds.), Policing sex (pp. 115-132). Abingdon and New York: Routledge.

Naezer, M., \& Ringrose, J. (2018). Adventure, intimacy, identity and knowledge: exploring how social media are shaping and transforming youth sexuality. In S. Lamb \& J. Gilber (Eds.), The Cambridge handbook of sexual development: childhood and adolescence (pp. 413-432). Cambridge: Cambridge University Press.

Naezer, M., Rommes, E., \& Jansen, W. (2017). Empowerment through sex education? Rethinking paradoxical policies. Sex Education, 17(6), 712-728.

Onwuegbuzie, A. J., Dickinson, W. B., Leech, N. L., \& Zoran, A. G. (2009). A qualitative framework for collecting and analyzing data in focus group research. International Journal of Qualitative Methods, 8(3), 1-21.

Phippen, A. (2012). Sexting: an exploration of practices, attitudes and influences. London: NSPCC and UK Safer Internet Centre Retrieved from: http://www.nspcc.org.uk/globalassets/documents/ research-reports/sexting-report-2012.

Powell, A. (2010). Sex, power and consent: youth culture and the unwritten rules. Melbourne: Cambridge University Press.

Renold, E. (2016). A young people's guide to making positive relationships matter. Cardiff University, Children's Commissioner for Wales, NSPCC Cymru, Welsh Government, Welsh Women's Aid. Retrieved from: https://www.nspcc.org.uk/services-and-resources/ research-and-resources/2016/agenda-young-peoples-guidepositive-relationships/. Accessed 5 June 2017

Ringrose, J., \& Harvey, L. (2015). "BBM is like match.com": social networking and the digital mediation of teen's sexual cultures? In J. Bailey \& V. Steeves (Eds.), eGirls, eCitizens: putting technology theory, policy \& education into dialogue with girls' and young women's voices (pp. 199-227). Canada: University of Ottawa Press.

Ringrose, J., Gill, R., Livingstone, S., \& Harvey, L. (2012). A qualitative study of children, young people and 'sexting': a report prepared for the NSPCC. London: NSPCC Retrieved from: http://eprints.lse.ac. uk/44216/1/ Libfile repository Content Livingstone $\% 2 \mathrm{C} \% 20 \mathrm{~S}$ A\%20qualitative $\% 20$ study $\% 20$ of $\% 20$ children $\% 2 \mathrm{C} \% 20$ young $\%$ 20people $\% 20$ and $\% 20 \% 27$ sexting $\% 27 \% 20 \% 28$ LSE $\% 20$ RO $\% 29$. pdf.

Ringrose, J., Harvey, L., Gill, R., \& Livingstone, S. (2013). Teen girls, sexual double standards and 'sexting': gendered value in digital image exchange. Feminist Theory, 14(3), 305-323.

Setty, E. (2018a). Meanings of bodily and sexual expression in youth sexting culture: young women's negotiation of gendered risks and harms. Sex Roles, 80(9-10), 586-606.

Setty, E. (2018b). Young people's attributions of privacy rights and obligations in digital sexting culture. International Journal of Communication, 12, 4533-4552.

Setty, E. (2019). 'Confident' and 'hot' or 'desperate' and 'cowardly'? Meanings of young men's sexting practices in youth sexting culture. Journal of Youth Studies. DOI. https://doi.org/10.1080/13676261. 2019.1635681.

Shariff, S., \& DeMartini, A. (2015). Defining the legal lines: eGirls and intimate images. In J. Bailey \& V. Steeves (Eds.), e Girls, eCitizens: putting technology theory, policy \& education into dialogue with girls' and young women's voices (pp. 281-305). Ottawa: University of Ottawa Press.

Simpson, B. (2013). Challenging childhood, challenging children: children's rights and sexting. Sexualities, 16(5/6), 690-709.

Starks, H., \& Trinidad, S. B. (2007). Choose your methods: a comparison of phenomenology, discourse analysis, and grounded theory. Qualitative Health Research, 17(10), 1372-1380.

Strauss, A., \& Corbin, J. (1998). Basics of qualitative research: techniques and procedures for developing grounded theory. Thousand Oaks: Sage Publications, Inc..

Symons, K., Ponnet, K., Walrave, M., \& Heirman, W. (2018). Sexting scripts in adolescent relationships: is sexting becoming the new norm? New Media \& Society, 20(10), 3836-3857.

Thomas, S. E. (2018). "What should I do?": young women's reported dilemmas with nude photographs. Sexuality Research \& Social Policy, 15, 192-207.

Tolman, D. L., Anderson, S. M., \& Belmonte, K. (2015). Mobilizing metaphor: considering complexities, contradictions and contexts in adolescent girls' and young women's sexual agency. Sex Roles, 73(7), 298-310.

UK Council for Child Internet Safety (2017). Sexting in schools and colleges: responding to incidents and safeguarding young people. Retrieved from: https://assets.publishing.service.gov.uk/ government/uploads/system/uploads/attachment_data/file/609874/ 6_2939_SP_NCA_Sexting_In_Schools_FINAL__Update_Jan 17. pdf. Accessed 20 Nov 2017

Van Ouytel, J., Walrave, M., \& Ponnet, K. (2018). Adolescent sexting research: the challenges ahead. JAMA Pediatrics, 172(5), 1-2.

Walker, S. J. (2012). Sexting and young people: a qualitative study. Masters Dissertation, University of Melbourne. Retrieved from: https://minervaaccess.unimelb.edu.au/bitstream/handle/11343/ 37683/287493_SJW\%20thesis\%207-11-12.pdf? sequence $=1$. Accessed 10 Nov 2014

Wilkingson, Y., Whitfield, C., Hannigan, S., Ali, P. A., \& Hayter, M. (2016). A qualitative meta-synthesis of young peoples' experiences of 'sexting'. British Journal of School Nursing, 11(4), 183-191.

Wolak, J., \& Finkelhor, F. (2016). Sextortion: findings from a survey of 1.631 victims. Crimes Against Children Research Center. Hampshire: University of New Hampshire. 